\title{
Plasma Nuclear Factor Kappa B and Serum Peroxiredoxin 3 in Early Diagnosis of Hepatocellular Carcinoma
}

\author{
Saber Ismail ${ }^{1}$, Wael Mayah ${ }^{1,5 *}$, Hassan El Battia ${ }^{4}$, Hanaa Gaballah ${ }^{2}$, Asif \\ Jiman-Fatani ${ }^{6}$, Hala Hamouda ${ }^{2}$, Mohamed A Afifi ${ }^{6}$, Nehal Elmashad ${ }^{3}$, Sherif EI \\ Saadany ${ }^{1,6}$
}

\begin{abstract}
Background: Early diagnosis of hepatocellular carcinoma (HCC) is the most important step in successful treatment. However, it is usually rare due to the lack of a highly sensitive specific biomarker so that the HCC is usually fatal within few months after diagnosis. The aim of this work was to study the role of plasma nuclear factor kappa B (NF-kB) and serum peroxiredoxin 3 (PRDX3) as diagnostic biomarkers for early detection of HCC in a high-risk population. Materials and Methods: Plasma nuclear factor kappa B level (NF-kB) and serum peroxiredoxin 3 (PRDX3) levels were measured using enzyme linked immunosorbent assay (ELISA), in addition to alpha-fetoprotein (AFP) in 72 cirrhotic patients, 64 patients with HCC and 29 healthy controls. Results: NF-kB and PRDX3 were significantly elevated in the HCC group in relation to the others. Higher area under curve (AUC) of 0.854 (for PRDX3) and 0.825 (for NF-kB) with sensitivity of $86.3 \%$ and $84.4 \%$ and specificity of 75.8\% and 75.4\% respectively, were found compared to AUC of alpha-fetoprotein (AFP) (0.65) with sensitivity of $72.4 \%$ and specificity of $64.3 \%$. Conclusions: NF- $\mathrm{kB}$ and PRDX3 may serve as early and sensitive biomarkers for early detection of HCC facilitating improved management. The role of nuclear factor kappa B (NF-kB) as a target for treatment of liver fibrosis and HCC must be widely evaluated.
\end{abstract}

Keywords: Nuclear factor kappa B - peroxiredoxin 3 - hepatocellular carcinoma - early diagnosis

Asian Pac J Cancer Prev, 16 (4), 1657-1663

\section{Introduction}

Hepatocellular carcinoma (HCC) is the fifth most prevalent cancer, thirdly leading cancer-related death worldwide (Iakova et al., 2011; Zhang et al., 2014). Chronic HBV and HCV are the major etiological factors of the disease (Cabibbo and Craxi, 2010). The mortality rates of patients with $\mathrm{HCC}$ remain very high (up to $94 \%$ ), making HCC the third common etiology of cancer-related death. Late detection in addition to lack of effective therapies for advanced stage of the disease may be the cause of such a high mortality rate (Bosch et al., 2004).

Currently, abdominal ultrasound and serum alphafetoprotein (AFP) are the most widely used methods for HCC detection. However, this does not reliably detect disease in early stage (Yamamoto et al., 2010). This could be due to the facts that ultrasonography is highly dependent on the experience of its operator (Poon et al., 2009) while elevated serum AFP level is the result of altered hepatocyte-hepatocyte interface associated with loss of normal architectural arrangement rather than necrosis or active regeneration (Tyson et al., 2011).
Triphasic CT with contrast is believed to be the optimal imaging technique for the detection and staging of HCC (Yu et al.,2004). The diagnostic efficacy of CT is markedly diminished in small tumors (less than $2 \mathrm{~cm}$ ) due to the hypo-vascularization of these small sized tumors (Gomaa et al., 2009).

Therefore, it is critical to identify and characterize sensitive and specific diagnostic biomarkers for early detection and treatment of HCC in high-risk populations (Altekruse et al., 2009; Huang et al., 2010). Recently, alternative serum biomarkers are being actively sought and proposed candidates that include nuclear factor kappa B (NF-kB) which plays a crucial role in bridging the action of growth factors and inflammation to hepatic oncogenesis (Beale et al., 2008). Activation of transcription factor NF-kB was reported as one of the early key events involved neoplastic progression of the liver (Arsura and Cavin, 2005).

Nuclear factor kappa B (NF-kB) was originally identified as a nuclear factor specific to $\mathrm{B}$ cells bound to the B site of the k-light chain gene enhancer. However NF-kB was later found to be expressed in other cell types

${ }^{1}$ Departments of Tropical Medicine \& Infectious Diseases, ${ }^{2}$ Medical Biochemistry, ${ }^{3}$ Clinical Oncology, Faculty of Medicine Tanta University, Tanta, ${ }^{4}$ Department of Tropical Medicine \& infectious Diseases, Faculty of Medicine, Kafrelsheikh University, Kafr Elsheikh, Egypt, ${ }^{5}$ Faculty of Dentistry, ${ }^{6}$ Department of Medical Microbiology and Parasitology, Faculty of Medicine, King Abdulaziz University, Jeddah, Saudi Arabia*For correspondence: waelmayah@gmail.com 
such as the liver epithelium, where it regulates hepatic cell proliferation and survival during regeneration and development. NF-kB controls the expression genes involved in the regulation of fundamental processes such as the immune response, cell adhesion, physical stress (e.g. liver regeneration), oxidative stress and cell survival (Hung et al., 2008).

Viral hepatitis causes a general inflammatory response in the liver, which is often followed by cirrhosis and HCC development. NF-kB seems to be crucially involved both in fibrogenesis and in the initiation and promotion of HCC in the chronically inflamed liver. Overall, activation of the $\mathrm{NF}-\mathrm{kB}$ signaling pathway by the action of proinflammatory mediators such as TNF- $\alpha$, chemokines, interleukins, and structural and non-structural viral proteins likely promotes survival of precancerous hepatocytes, thereby favoring their conversion to a malignant phenotype through subsequent genetic lesions (Bouchard et al., 2011).

The interplay between NF-kB and growth factors implicated in invasion and metastasis has raised the hypothesis that NF-kB might also play a role in the promotion of hepatic metastasis (Nugler et al., 2008).

Majority of studies have demonstrated that the progression of HCC is closely correlated to oxidative stress (Jo et al., 2011). Cancer cells usually exhibit changes in key mitochondrial regulators of cell death or mitochondrial structure and function which are different from those of normal cells. This enables them to use antioxidant systems to maintain the redox balance under high levels of oxidative stress (Trachootham et al., 2009).

Classical antioxidant genes related to cancer include superoxide dismutase (SOD), catalase, glutathione peroxidase, peroxiredoxins (PRDXs), and thioredoxin (Trx) (Basu et al., 2011; Marra et al., 2011). Peroxiredoxin 3 (PRDX3) was identified as a member of the peroxiredoxin protein family (Prx), which acts as a cellular defense system against oxidative stress and play important roles in peroxide detoxification, and belong to a family of thiol-specific antioxidant enzymes catalyzing the reduction of hydrogen peroxide $(\mathrm{H} 2 \mathrm{O} 2)$ in the presence of thioredoxin. Its catalytic activity and protein sequences are different from those of other antioxidants (Dietz et al., 2002). Overexpression of PRDX3 has been reported in mesothelioma, HCC, breast cancer, and ovarian cancer, suggesting that it may be involved in tumorgenesis and cancer progression (Huh et al., 2012).

The aim of the work is to study the role of plasma nuclear factor kappa $\mathrm{B}(\mathrm{NF}-\mathrm{kB})$ and serum peroxiredoxin 3 (PRDX3) as sensitive and specific diagnostic biomarkers for early detection and treatment of early HCC in highrisk populations.

\section{Materials and Methods}

This study was carried out on 136 patients presenting to Tropical Medicine Department or its outpatient clinics in Tanta University Hospital, after ethical committee approval. In addition 29 healthy subjects represented the control group. They were 97 males and 68 females, their ages ranged between 33-65 years. They were classified as follows: Group I (control): included 29 healthy individuals. They were 16 males and 13 females. Their ages ranged between 33-48 years; Group II (liver cirrhosis): included 72 patients with liver cirrhosis. Diagnosis of liver cirrhosis was based on clinical picture, biochemical, ultrasonographic criteria, and pathological data, without any evidence of hepatic focal lesions. They were 43 males and 29 females. Their ages ranged between 46 -65 years; Group III (HCC): included 64 patients with HCC diagnosed according to AASLD practice guidelines for HCC diagnosis (Bruix and Sherman, 2005). They were 38 males and 26 females. Their ages ranged between 42 -63 years.

\section{Exclusion criteria}

Patients who refuse to sign consent, patients with previous treatment of HCC, presence of extra-hepatic metastasis, patients with other causes of chronic liver disease (e.g. Hemochromatosis, Wilson's disease autoimmune hepatitis), patients with metastatic liver disease, patients with sepsis, acute infections, rheumatoid arthritis, systemic lupus erythematous, chronic obstructive pulmonary disease, pulmonary tuberculosis and Cushing syndrome.

All patient and control groups were subjected to the following: i) Thorough history taking; ii) Clinical examination: with special stress on signs of liver cell failure, hepatomegaly, splenomegaly and/or ascites; iii) Routine laboratory investigations, including complete blood picture, blood urea and serum creatinine; iv) Detection of hepatitis $\mathrm{C}$ virus by $3^{\text {rd }}$ generation ELISA and Polymerase Chain Reaction (PCR) for HCV RNA (Wilkins et al., 2010); v) Detection of hepatitis B virus by HBV surface antigen (Chan et al., 2002); vi) Liver function tests including total and direct serum bilirubin, serum alanine aminotransferase (ALT), serum aspartate aminotransferase (AST), serum albumin and prothrombin time and activity; vii) Estimation of alpha fetoprotein level (AFP) (Macias-Rodriguez et al., 2000); viii) Abdominal Imaging: Abdominal ultrasonography was done for all patients \& controls, while Triphasic CT scans were done for patients groups (GII \& GIII); ix) Blood sampling: Peripheral venous blood samples were taken from all patients and controls under complete aseptic condition after overnight fasting. The blood sample of each subject was divided into two halved; the $1^{\text {st }}$ half was collected into the available EDTA-treated tubes; the tubes were centrifuged for 20 minutes at $1000 \times \mathrm{g}$ to obtain plasma (for plasma NF-kB level measurement). The other half was collected into sterile tubes without additive and centrifuged at $3500 \times \mathrm{g}$ for 5 minutes at room temperature. Supernatants were transferred into Eppendorf tubes and centrifuged at $12000 \times \mathrm{g}$ for $10 \mathrm{~min}$ to remove cellular fractions to obtain serum (for serum PRDX3 measurement). All obtained plasma and serum samples were aliquoted, frozen and stored at $\left(-80^{\circ} \mathrm{C}\right)$ till the time of biochemical examination.

\section{Measurement of plasma nuclear factor Kappa B level}

NF-kB level was estimated by ELISA kit supplied by Unique product Superb quality Client favorite Nicest service (USCN) made in USA, purchased from new test 
Plasma Nuclear Factor Kappa B and Serum Peroxiredoxin 3 in Early Diagnosis of Hepatocellular Carcinoma

company. The microtiter plate provided in this kit has been pre-coated with an antibody specific to nuclear factor Kappa B (NF- KB). Standards or samples are then added to the appropriate micro titer plate wells with a biotinconjugated antibody preparation specific for NF-kB. Next, Avidin conjugated to horseradish peroxidase (HRP) is added to each microplate well and incubated. After TMB substrate solution is added, only those wells that contain NF-kB, biotin-conjugated antibody and enzymeconjugated avidin will exhibit a change in color. The enzyme substrate reaction is terminated by the addition of sulphuric acid solution and the color change is measured spectrophotometrically at a wavelength of $450 \mathrm{~nm}$. The concentration of NF-kB in the samples is then determined by comparing the optical density (O. D.) of the samples to the standard curve (Punsawad et al, 2012).

\section{Measurement of serum peroxiredoxin 3 (PRDX3)}

PRDX3 levels were measured using a commercially available enzyme-linked immunosorbent assay (ELISA) kit (BioVender research and Diagnostic Products, USA, Canada and Mexico (Nonn et al, 2003).

\section{Assay Procedure}

Allow all reagents to reach room temperature before use. Gently mix all liquid reagents prior to use. All standards, controls and samples should be run in duplicate for confirmation of reproducibility. Determine the number of 16-well strips needed for assay. Insert these in the frame(s) for current use. Add $300 \mu$ l of Incubation buffer to all wells and incubate the plate for 5 minutes at room temperature. Thoroughly aspirate the solution from the wells. Wash wells 2 times. For the standard curve, add $100 \mu \mathrm{l}$ of the standard to the appropriate microtiter wells. Add $100 \mu$ l of the Standard/Sample Dilution Buffer to zero wells. Serum requires at least 30 fold dilution in the Standard/Sample Dilution Buffer. And add $100 \mu \mathrm{l}$ of diluted samples to each well. Cover the plate with the plate cover and incubate for $2 \mathrm{~h}$ at room temperature. Thoroughly aspirate from the wells. Wash the wells 3 times. Pipette $100 \mu \mathrm{l}$ of "Working Secondary Antibody Solution" into each well. Cover the plate with the plate cover and incubate for $1 \mathrm{~h}$ at room temperature. Thoroughly aspirate from the wells. Wash the wells 3 times. Add $100 \mu \mathrm{l}$ "Working AV-HRP Solution" to each well. Cover the plate with the plate cover and incubate for 30 minutes at room temperature. Thoroughly aspirate or decant the solution from the wells. Wash the wells 3 times. Pour enough Substrate you need into a tube or reagent boat. Add $100 \mu \mathrm{l}$ of Substrate to each well. The liquid in the wells should begin to turn blue. Incubate the plate at room temperature. Avoid exposing the microtiter plate to direct sunlight. Do not cover the plate with aluminum foil (or other metal), or color may develop. The incubation time for chromogen substrate is often determined by the microtiter plate reader used. O.D. values should be monitored and the substrate reaction stopped before O.D. of the positive wells exceeds the limits of the instrument. O.D. values at $450 \mathrm{~nm}$ can only be read after the Stop Solution has been added to each well. Keep the plate away from sun light

Table 1. Comparison of Liver Function Tests, Alpha-fetoprotein (AFP), Nuclear Factor Kappa B (NF-kB) and Peroxiredoxin 3 (PRDX3) in the Studied Groups

\begin{tabular}{|c|c|c|c|c|}
\hline & $\begin{array}{c}\text { GI } \\
\text { (control) }\end{array}$ & $\begin{array}{c}\text { GII } \\
\text { (liver cirrhosis) }\end{array}$ & $\begin{array}{c}\text { GIII } \\
\text { (HCC group) }\end{array}$ & Tukey's test \\
\hline Total bilirubin (mg/dl) & $0.53 \pm 0.23$ & $2.46 \pm 1.91$ & $1.96 \pm 0.63$ & $\begin{array}{l}\mathrm{p} 1<0.001^{*} \\
\mathrm{p} 2=0.002^{*} \\
\mathrm{p} 3=0.538\end{array}$ \\
\hline Direct bilirubin (mg/dl) & $0.15 \pm 0.06$ & $0.91 \pm 0.73$ & $0.91 \pm 0.43$ & $\begin{array}{l}\text { p1<0.001* } \\
\text { p2<0.001* } \\
\text { p3 }=1\end{array}$ \\
\hline $\operatorname{ALT}(\mathrm{I} . \mathrm{U} / \mathrm{L})$ & $22.27 \pm 8.76$ & $34.13 \pm 16.92$ & $37.87 \pm 20.71$ & $\begin{array}{l}\mathrm{p} 1=0.122 \\
\mathrm{p} 2=0.023^{*} \\
\mathrm{p} 3=0.893\end{array}$ \\
\hline AST (I.U/L) & $24.93 \pm 7$ & $54.9 \pm 21.71$ & $59.4 \pm 47.45$ & $\begin{array}{l}\mathrm{p} 1=0.016^{*} \\
\mathrm{p} 2=0.004 * \\
\mathrm{p} 3=0.96\end{array}$ \\
\hline Albumin (g/dl) & $4.05 \pm 0.26$ & $2.65 \pm 0.32$ & $2.49 \pm 0.25$ & $\begin{array}{l}\text { p1<0.001* } \\
\text { p2<0.001* } \\
\text { p3 }=0.52\end{array}$ \\
\hline Prothrombin activity (\%) & $95.8 \pm 4$ & $70.4 \pm 14$ & $64.7 \pm 6.1$ & $\begin{array}{l}\text { p1<0.001* } \\
\text { p2<0.001* } \\
\text { p3 }=0.345\end{array}$ \\
\hline Alpha-fetoprotein (AFP) (ng/mL) & $6.3 \pm 1.2$ & $10.55 \pm 5.7$ & $993.8 \pm 965.58$ & $\begin{array}{l}\text { p1 }=0.99 \\
\text { p }<<0.001 * \\
\text { p3 }<0.001 *\end{array}$ \\
\hline $\begin{array}{l}\text { Nuclear factor kappa B } \\
(\mathrm{NF}-\mathrm{kB})(\mathrm{ng} / \mathrm{mL})\end{array}$ & $10 \pm 1.54$ & $145.8 \pm 53.5$ & $255.5 \pm 54$ & $\begin{array}{l}\text { p1<0.001* } \\
\text { p2<0.001* } \\
\text { p3<0.001* }\end{array}$ \\
\hline Peroxiredoxin 3 (PRDX3) (ng/mL) & $52.3 \pm 26.8$ & $132.3 \pm 96.5$ & $304.3 \pm 204.48$ & $\begin{array}{l}\text { p1 }=0.026^{*} \\
\text { p2<0.001* } \\
\text { p3<0.001* }\end{array}$ \\
\hline
\end{tabular}

*Significant values (p<0.05); P1: GI vs GII; P2: GI vs GIII; P3: GII vs GIII 
because the Substrate is light sensitive. Typically, reaction is stopped 5 10 minutes after treatment of Substrate, but this time can be adjusted as the user desires. Add $100 \mu \mathrm{l}$ of Stop Solution to each well. The solution in the wells should change from blue to yellow. Read the absorbance of each well at $450 \mathrm{~nm}$. Read the plate within 20 minutes of adding the Stop Solution (Nonn et al, 2003).

\section{Statistical analysis}

Statistical analysis was performed using Sigma Stat software version 2. The results were expressed by mean \pm standard deviation (SD) the comparison was made by one way ANOVA on rank test (Tukey's test). p value less than 0.05 was considered statistically significant. The diagnostic accuracy of each of the candidate biomarkers was evaluated using receiver operating characteristic (ROC) curve analysis, reporting the area under the curve (AUC) and its 95\% confidence interval (CI). The diagnostic cut-off values and the related sensitivity and specificity were determined.

\section{Results}

Table (1) showed comparison of liver function tests, alpha-fetoprotein (AFP), plasma nuclear factor kappa $\mathrm{B}(\mathrm{NF}-\mathrm{kB})$ and serum peroxiredoxin 3 (PRDX3) in the studied groups. Significant differences were observed between the diseased groups (II \&III) and the control group (GI) as regards liver function tests $(\mathrm{p}<0.05)$ except for ALT levels between the control (GI) and the cirrhotic liver group (GII) ( $\mathrm{p}>0.05)$.

Significant differences were observed between all studied groups regarding measured NF- $\mathrm{KB}$ and PRDX3 $(\mathrm{p}<0.05)$.

Serum alpha-fetoprotein levels showed significant differences between HCC group (GIII) in comparison to the control group (GI) and the cirrhotic liver group (GII) $(\mathrm{p}<0.05)$ and a non-significant difference was detected between the control group (GI) and the cirrhotic liver group (GII) $(\mathrm{p}>0.05)$.

Receiver operating characteristic (ROC) curve analyses suggested that serum PRDX3 and plasma NF-kB expression are useful biomarkers for detecting patients

Table 2. ROC Curve Analysis, Sensitivity and Specificity of Peroxiredoxin 3, NF-kB and AFP

\begin{tabular}{llcc}
\hline & AUC & Sensitivity (\%) & Specificity (\%) \\
\hline PRDX3 (ng/mL) & 0.854 & 86.3 & 75.8 \\
NF-kB(ng/mL) & 0.825 & 84.4 & 75.4 \\
AFP $(\mathrm{ng} / \mathrm{mL})$ & 0.65 & 72.4 & 64.3 \\
\hline
\end{tabular}

Table 3. Correlation between the Studied Parameters

\begin{tabular}{llll}
\hline & PRDX3 $(\mathrm{ng} / \mathrm{mL})$ & AFP $(\mathrm{ng} / \mathrm{mL})$ & Size $\left(\mathrm{cm}^{2}\right)$ \\
\hline NF-kB $(\mathrm{ng} / \mathrm{mL})$ & $\mathrm{r}=0.257$ & $\mathrm{r}=0.353$ & $\mathrm{r}=0.376$ \\
& $\mathrm{P}=0.04^{*}$ & $\mathrm{P}=0.004^{*}$ & $\mathrm{P}=0.002^{*}$ \\
PRDX3 (ng/mL) & - & $\mathrm{r}=0.058$ & $\mathrm{r}=0.35$ \\
& & $\mathrm{P}=0.64$ & $\mathrm{P}=0.0045^{*}$ \\
AFP $(\mathrm{ng} / \mathrm{mL})$ & - & - & $\mathrm{r}=0.181$ \\
& & & $\mathrm{P}=0.15$ \\
\hline *Significant values $(\mathrm{p}<0.05) ; \mathrm{r}=$ Correlation coefficient &
\end{tabular}

*Significant values $(\mathrm{p}<0.05) ; \mathrm{r}=$ Correlation coefficient with HCC. Both serum PRDX3 and plasma NF-kB showed a higher area under curve (AUC) of $0.854(95 \%$ CI) for PRDX3 and 0.825(95\% CI) for NF-KB. At a cutoff value of $156.3 \mathrm{ng} / \mathrm{mL}, \mathrm{PRDX} 3$ sensitivity and specificity was $86.3 \%$ and $75.8 \%$ respectively. While, NF-kB at a cutoff value of $193.24 \mathrm{ng} / \mathrm{mL}$ showed sensitivity and specificity of $72.4 \%$ and $75.4 \%$ respectively. On the other hand AFP showed AUC of (0.65) with sensitivity of 72.4\% and specificity of $64.3 \%$ (Table 2).

Table (3) showed that both NF-kB and PRDX3 were positively correlated with each other and with the size of HCC mass. Moreover, a significantly positive correlation was reported between AFP and NF-KB but not between AFP and PRDX3 or the size of mass.

\section{Discussion}

Hepatocellular carcinoma (HCC) is the fifth most prevalent cancer, thirdly leading cancer-related death worldwide (Iakova et al., 2011; Zhang et al., 2014). HCC develops on a background of chronic liver disease, such as chronic inflammation or cirrhosis (Zekri et al., 2013). The incidence and mortality rates for HCC are nearly identical, indicating the overall poor survival of patients with this tumor. Therefore, the most effective treatment relies on the early diagnosis of hepatocellular carcinoma (Bruix and Sherman, 2005). The early detection of HCC is usually rare making it fatal within few months after diagnosis (Thomas and Zhu, 2005). Most imaging techniques help to discover HCC after considerable time of onset. In most instances, oncologists depend on AFP as the commonest and feasible marker for assessing $\mathrm{HCC}$ in addition to imaging. However, AFP is not completely reliable marker in early HCC diagnosis, prevention or therapy due to its low specificity and sensitivity (Teofanescu et al., 2010; youns et al., 2013). Liver biopsy is always considered as an invasive procedure, so biochemical findings are still greatly appreciated (Makuuchi et al., 2008).

The ideal hepatic tumor biomarkers should possess high specificity and sensitivity, should be easily accessible, easily measurable, minimally invasive, inexpensive, accurate, and acceptable to patients and physicians (Mendy and Walton, 2009).

In the current work, we tried to detect the clinical value of both plasma nuclear factor kappa B (NF-kB) and serum peroxiredoxin 3 (PRDX3) and their role as valuable biomarkers for early HCC detection. Peroxiredoxin 3 (PRDX3) is a c-Myc target gene that is required for mitochondrial homeostasis and neoplastic transformation and predominantly localizes in the mitochondria (Wonsey et al., 2002). Moreover, PRDX3 might serve as a first-line of host defense against reactive oxygen species and in protecting cells from $\mathrm{H} 2 \mathrm{O} 2$-induced apoptosis (Rabilloud et al., 2002).

We found AFP significantly elevated in the HCC group in relation to the other two groups $(\mathrm{p}<0.05)$ without any significant difference between the group of liver cirrhosis and healthy control $(\mathrm{p}>0.05)$. This is in agreement with Nagaoka et al. (2003) who found that the mean plasma concentration of alpha fetoprotein was significantly higher in patients with hepatocellular carcinoma as compared to 
patients with chronic liver disease.

However, 18 out of $64 \mathrm{HCC}$ patients $(28.1 \%)$ showed AFP value less than or equal to $400 \mathrm{ng} / \mathrm{dl}$ which strengthen that, AFP is not completely reliable marker in early HCC diagnosis, prevention or therapy due to its low specificity and sensitivity (Teofanescu et al., 2010; youns et al., 2013).

In our study we tried to evaluate the value of nuclear factor kappa B (NF-kB) and peroxiredoxins (PRDX3) as sensitive biomarkers for early and reliable detection of HCC. We found both NF-kB and PRDX3 to be significantly elevated in the HCC groups in relation to the other groups. Moreover, serum PRDX3 and plasma NF-kB showed a higher AUC of 0.854 (for PRDX3) and 0.825 (for NF-kB) with sensitivity of $86.3 \%$ and $84.4 \%$ and specificity of $75.8 \%$ and $75.4 \%$ respectively compared to AUC of AFP (0.65) with sensitivity of $72.4 \%$ and specificity of $64.3 \%$.

These results are in agreement with Arsura and Cavin (2005) who reported an increased NF-kB level in HCC patients which may be due to its constitutive activation of the early key events involved in neoplastic progression of the liver. It has been revealed that a number of proinflammatory mediators such as TNF- $\alpha$, chemokines, interleukins contribute in the progression of chronic liver disease, many of which are either targets or activators of nuclear factor-KB (NF-kB) (Bonacchi et al., 2003; Seki et al, 2007; Dominguez, et al, 2009; Guo, et al., 2009 and Miura, et al, 2010).

Wu et al. (2009) observed that hepatic NF-kB mRNA was aberrantly overexpressed during the course of rat hepatocarcinogenesis. Moreover, Yokoo et al. (2011) reported a constitutive activation of NF- $\mathrm{KB}$ in human $\mathrm{HCC}$ tissue samples compared to surrounding liver tissues. This is supported by the recent study of Gaballah et al which provided evidence that active $\mathrm{NF}-\varkappa \mathrm{B}$ signaling has a major contribution to the molecular pathogenesis of human hepatocellular carcinoma. They also concluded that, the association between NF- $x \mathrm{~B}$ activity and expression levels with the bad prognostic parameters for HCC potentiates their value as prognostic markers to predict treatment outcome, metastasis or recurrence (Gaballah et al., 2014).

Luedde and Schwabe (2011) proposed that NF-KB acts as a central link between hepatic injury, fibrosis and $\mathrm{HCC}$, and that it may represent a target for the prevention or treatment of liver fibrosis and HCC.

Concomitantly Sunami et al. (2012) revealed that hepatic activation of NF-kB is sufficient to induce liver fibrosis by a way of macrophage-mediated chronic inflammation. Therefore, agents controlling the hepatic $\mathrm{NF}-\mathrm{kB}$ system represent attractive therapeutic tools to prevent fibrosis development in chronic liver diseases. Moreover, it was reported that Inhibition of NF-kB may enhances the antitumor effect of tumor necrosis factor- $\alpha$ gene therapy for hepatocellular carcinoma in mice (Haruki et al., 2013).

A number of different factors may trigger activation of NF-kB during hepatocarcinogenesis. In HBV-induced $\mathrm{HCC}$, it has been suggested that the oncogenic HBV $\mathrm{X}$ protein activates the NF-kB signaling pathway. This up regulation might promote progression of HCC via proliferative and anti-apoptotic effects, as well as the spreading of liver tumor cells (Zhang et al., 2010).

NF-kB activation is also detected in $\mathrm{HCV}$ via core protein. Moreover, many patients with advanced liver disease display increased activation of NF- $\mathrm{kB}$ in the liver (Tai, et al., 2000; Schwabe et al., 2006).

It was confirmed that PRDX3 expression may play an important role in hepatocarcinoma progression. Qiao et al. (2012) has analyzed the comparative proteomic profiles between HCC tumors and adjacent non-tumor tissues using two-dimensional gel electrophoresis and MALDI-TOF MS. They indicated that over-expression of PRDX3 was associated with $94.9 \% \mathrm{HCC}$, which was significantly higher than that in non-tumor tissues. Moreover, this over-expression of PRDX3 was correlated with poor differentiation of HCC suggesting that PRDX3 has substantial clinical impact on the progression of hepatocarcinoma, and may be a potential therapeutic target for HCC.

Several studies have showed that PRDX3 is overexpressed in many cancers like prostate cancer, cervical cancer, colorectal cancer, and ovarian adenocarinoma. Aggressively growing cancer cells produce high levels of ROS that disturb the redox balance. PRDX3 is an active responder to oxidative stress, and its expression is augmented to remove cellular ROS and inhibit apoptosis, which is beneficial to cancer growth and invasion (Kim et al., 2009; Li et al., 2009; Liu et al., 2010; Wu et al., 2010).

Our findings were in agreement with that of Shi et al. (2014) who found serum PRDX3 to be significantly higher in HCC patients than in the patients with liver cirrhosis and healthy control. The sensitivity and specificity of serum PRDX3 for the diagnosis of HCC were $85.9 \%$ and $75.3 \%$, respectively. They concluded that, serum PRDX3 can be used as a noninvasive biomarker for the diagnosis and/or prognosis of HCC.

In conclusion, both nuclear factor kappa $\mathrm{B}(\mathrm{NF}-\mathrm{kB})$ and peroxiredoxin 3 (PRDX3) may serve as early and sensitive biomarkers for early detection of HCC making early management and control more possible. The role of nuclear factor kappa $\mathrm{B}(\mathrm{NF}-\mathrm{kB})$ as a target for prevention and treatment of liver fibrosis and HCC must be widely studied.

\section{References}

Altekruse SF,McGlynn KA, Reichman ME (2009). Hepatocellular carcinoma incidence, mortality, and survival trends in the United States from 1975 to 2005. J Clin Oncol, 27, 1485-91.

Arsura M, Cavin LG (2005). Nuclear factor-kappaB and liver carcinogenesis. Cancer Lett, 229, 157-69.

Basu A, Banerjee H, Rojas H, et al (2011). Differential expression of peroxiredoxins in prostate cancer: consistent upregulation of PRDX3 and PRDX4. Prostate, 71, 755-65.

Beale G, Chattopadhyay D, Gray J, et al (2008). AFP, PIVKAII, GP3, SCCA-1 and follisatin as surveillance biomarkers for hepatocellular cancer in non-alcoholic and alcoholic fatty liver disease. BMC Cancer, $\mathbf{8}, 200-8$.

Bonacchi A, Petrai I, Defranco RM, et al (2003). The chemokine CCL21 modulates lymphocyte recruitment and fibrosis in chronic hepatitis C. Gastroenterology, 125, 1060-76.

Bosch FX, Ribes J, Diaz M, Cleries R (2004). Primary liver 
cancer: worldwide incidence and trends. Gastroenterology, 127, 5-16.

Bouchard MJ, Navas-Martin S (2011). Hepatitis B and C virus hepatocarcinogenesis: lessons learned and future challenges. Cancer Lett, 305, 123-43.

Bruix J, Sherman M (2005). Practice guidelines committee, American association for the study of liver diseases. management of hepatocellular carcinoma. Hepatology, 42, 1208-36.

Cabibbo G, Craxi A (2101). Epidemiology, risk factors and surveillance of hepatocellular carcinoma. Eur Rev Med Pharmacol Sci, 14, 352-5.

Chan HL, Tsang SW, Leung NW, et al (2002). Occult HBV infection in cryptogenic liver cirrhosis in an area with high prevalence of HBV infection. Am J Gastroenterol, 97, 1211-5.

Dietz KJ, Horling F, Konig J, Baier M (2002). The function of oroplast 2-cysteine peroxiredoxin in peroxide detoxification and its regulation. $J$ Exp Bot, 53, 1321-9.

Dominguez I, Sonenshein GE, Seldin DC (2009). Protein kinase CK2 in health and disease: CK2 and its role in Wnt and NFkappaB signaling: linking development and cancer. Cell Mol Life Sci, 66, 1850-7.

Gaballah HH, Zakaria SS, Ismail SA (2014). Activity and expression pattern of NF- $\varkappa$ B /P65 in peripheral blood from hepatocellular carcinoma patients - link to hypoxia inducible factor-1 $\alpha$. Asian Pac J Cancer Prev, 15, 6911-7.

Gomaa AJ, Khan SA, Leen EL, Waked I, Taylor-Robinson SD (2009). Diagnosis of hepatocellular carcinoma. World J Gastroenterol, 15, 1301-14.

Guo J, Loke J, Zheng F, et al (2009). Functional linkage of cirrhosis-predictive single nucleotide polymorphisms of Toll-like receptor 4 to hepatic stellate cell responses. Hepatology, 49, 960-8.

Haruki K, Shiba H, Fujiwara Y, et al (2013). Inhibition of nuclear factor- $x \mathrm{~B}$ enhances the antitumor effect of tumor necrosis factor- $\alpha$ gene therapy for hepatocellular carcinoma in mice. Surgery, 154, 468-78.

Huang HC, Zheng S, VanBuren V, Zhao Z (2010). Discovering disease-specific biomarker genes for cancer diagnosis and prognosis. Technol Cancer Res Treat, 9, 219-30.

Huh JY, Kim Y, Jeong J, et al (2012). Peroxiredoxin 3 is a key molecule regulating adipocyte oxidative stress, mitochondrial biogenesis, and adipokine expression. Antioxid Redox Signal, 16, 229-43.

Hung CH, Lee CM, Kuo FY, et al (2008). Steatosis correlates with hepatic expression of death receptors and activation of nuclear factor-kappaB in chronic hepatitis C. Liver Int, 28, 339-46.

Iakova P, Timchenko L, Timchenko NA (2011). Intracellular signaling and hepatocellular carcinoma. Semin Cancer Biol, 21, 28-34.

Jo M, Nishikawa T, Nakajima T, et al (2011). Oxidative stress is closely associated with tumor angiogenesis of hepatocellular carcinoma. J Gastroenterol, 46, 809-21.

Kim K, Yu M, Han S et al (2009). Expression of human peroxiredoxin isoforms in response to cervical carcinogenesis. Oncol Rep, 21, 1391-6.

Li XQ, Zhang SL, Cai Z, et al (2009). Proteomic identification of tumor-associated protein in ovarian serous cystadenocarinoma. Cancer Lett, 275, 109-16.

Liu X, Feng R, Du L (2010). The role of enoyl-CoA hydratase short chain 1 and peroxiredoxin 3 in PP2-induced apoptosis in human breast cancer MCF-7 cells. FEBS Lett, 584, 3185-92.

Luedde T, Schwabe RF (2011). NF-xB in the liver-linking injury, fibrosis and hepatocellular carcinoma. Nat Rev Gastroenterol
Hepatol, 8, 108-18.

Macias Rodriguez MA, Rendon Unceta P, Tejada Cabrera M, et al (2000). Risk factors for hepatocellular carcinoma in patients with liver cirrhosis. Rev Esp Enferm Dig, 92, 458-69.

Makuuchi M, Kokudo N, Arii S, et al (2008). Development of evidence-based clinical guidelines for the diagnosis and treatment of hepatocellular carcinoma in Japan. Hepatol Res, 38, 37-51.

Marra M, Sordelli IM, Lombardi A, et al (2011). Molecular targets and oxidative stress biomarkers in hepatocellular carcinoma: an overview. J Transl Med, 10, 9:171.

Mendy M, Walton R (2009). Molecular pathogenesis and early detection of hepatocellular carcinoma-perspectives from West Africa. Cancer Lett, 286, 44-51.

Miura K, Kodama Y, Inokuchi S, et al (2010). Toll-like receptor 9 promotes steatohepatitis by induction of interleukin-1beta in mice. Gastroenterology, 139, 323-34.

Nagaoka S, Yatsuhashi H, Hamada H, et al (2003). The desgamma-carboxy prothrombin index is a new prognostic indicator for hepatocellular carcinoma. Cancer, 98, 2671-7.

Naugler WE, Karin M (2008). NF-kappa B and canceridentifying targets and mechanisms. Curr Opin Genet Dev, 18, 19-26.

Nonn L, Berggren M, Powis G (2003). Increased expression of mitochondrial peroxiredoxin-3 (thioredoxin peroxidase-2) protects cancer cells against hypoxia and drug-induced hydrogen peroxide-dependent apoptosis. Mol Cancer Res, 1, 682-9.

Poon D, Anderson BO, Chen LT, et al (2009). Management of hepatocellular carcinoma in Asia: consensus statement from the Asian Oncology Summit. Lancet Oncol, 10, 1111-8.

Punsawad C, Krudsood S, Maneerat Y, et al (2012). Activation of nuclear factor kappa B in peripheral blood mononuclear cells from malaria patients. Malar J, 11, 191 .

Qiao B, Wang J, Xie J, et al (2012). Detection and identification of peroxiredoxin 3 as a biomarker in hepatocellular carcinoma by a proteomic approach. Int J Mol Med, 29, 832-40.

Rabilloud T, Heller M, Gasnier F, et al (2002). Proteomics analysis of cellular response to oxidative stress. Evidence for in vivo overoxidation of peroxiredoxins at their active site. J Biol Chem, 277, 19396-401.

Schwabe RF, Seki E, Brenner DA (2006). Toll-like receptor signaling in the liver. Gastroenterology, 130, 1886-900.

Seki E, De Minicis S, Osterreicher CH, et al (2007). TLR4 enhances TGF-beta signaling and hepatic fibrosis. Nat Med, 13, 1324-32.

Shi L, Wu LL, Yang JR, et al (2014). Serum peroxiredoxin3 is a useful biomarker for early diagnosis and assessment of prognosis of hepatocellular carcinoma in Chinese patients. Asian Pac J Cancer Prev, 15, 2979-86

Sunami Y, Leithäuser F, Gul S, et al (2012). Hepatic activation of IKK/NF $x \mathrm{~B}$ signaling induces liver fibrosis via macrophagemediated chronic inflammation. Hepatology, 56, 1117-28.

Tai DI, Tsai SL, Chen YM, et al (2000). Activation of nuclear factor kappaB in hepatitis $\mathrm{C}$ virus infection: implications for pathogenesis and hepatocarcinogenesis. Hepatology, 31, 656-64.

Teofanescu I, Gologan E, Stefanescu E, Balan G (2010). Surveillance of cirrhosis for hepatocellular carcinoma-clinical validation of new serological biomarkers for improved diagnosis. Rev Med Chir Soc Med Nat Iasi, 114, 39-46.

Thomas M, Zhu A (2005). Hepatocellular carcinoma: the need for progress. J Clin Oncol, 23, 2892-9.

Trachootham D, Alexandre J, Huang P (2009). Targeting cancer cells by ROS-mediated mechanisms: a radical therapeutic approach? Nat Rev Drug Discov, 8, 579-91. 
Tyson GL, Duan Z, Kramer JR, Davila JA, Richardson PA

(2011). Level of $\alpha$-fetoprotein predicts mortality among patients with hepatitis C-related hepatocellular carcinoma. Clin Gastroenterol Hepatol, 9, 989-94.

Wilkins T, Malcolm JK, Raina D, Schade RR (2010). Hepatitis C: diagnosis and treatment. Am Fam Physician, 81, 1351-7.

Wonsey DR, Zeller KI, Dang CV (2002). The c-Myc target gene PRDX3 is required for mitochondrial homeostasis and neoplastic transformation. Proc Natl Acad Sci U S A, 99, 6649-54.

Wu W, Yao DF, Qiu LW, et al (2009). Characteristics of hepatic nuclear-transcription factor-kappa B expression and quantitative analysis in rat hepatocarcinogenesis. Hepatobiliary Pancreat Dis Int, 8, 504-9.

Wu XY, Fu ZX, Wang XH (2010). Peroxiredoxins in colorectal neoplasms. Histol Histopathol, 25, 1297-303.

Yamamoto K, Imamura H, Matsuyama Y, et al (2010). AFP, AFP-L3, DCP, and GP73 as markers for monitoring treatment response and recurrence and as surrogate markers of clinicopathological variables of HCC. J Gastroenterol, 45, 1272-82.

Yokoo H, Yasuda J, Nakanishi K, et al (2011). Clinicopathological significance of nuclear factor- $x \mathrm{~B}$ activation in hepatocellular carcinoma. Hepatol Res, 41, 240-9.

Youns MM, Abdel Wahab AH, Hassan ZA, Attia MS (2013). Serum talin-1 is a potential novel biomarker for diagnosis of hepatocellular carcinoma in Egyptian patients. Asian Pac J Cancer Prev, 14, 3819-23.

Yu SC, Yeung DT, So NM (2004). Imaging features of hepatocellular carcinoma. Clin Radiol, 59, 145-56.

Zekri Ael-R, Nassar AA, El-Din El-Rouby MN, et al (2013). Disease progression from chronic hepatitis $\mathrm{C}$ to cirrhosis and hepatocellular carcinoma is associated with increasing DNA promoter methylation. Asian Pac J Cancer Prev, 14, 6721-6.

Zhang F, Wang Q, Ye L, Feng Y, Zhang X (2010). Hepatitis $\mathrm{B}$ virus $\mathrm{X}$ protein upregulates expression of calpain small subunit 1 via nuclear factor-kappaB/p65 in hepatoma cells. J Med Virol, 82, 920-8.

Zhang ZM, Zhang YM, Gao S, et al (2014). Treatment efficacy and prognostic factors for huge HCC based on Barcelona clinic liver cancer staging. Asian Pac J Cancer Prev, 15, 8823-8. 